\title{
DIGITAL TRANSFORMATION: CONSTRUCT DEFINITION CHALLENGES AND SCENARIOS FOR A RESEARCH AGENDA
}

\author{
RODRIGO B. CARVALHO ${ }^{1}$ \\ https://orcid.org/0000-0003-3716-0879 \\ ANTÓNIO M. P. REIS \\ https://orcid.org/0000-0001-7626-0536 \\ CLÁUDIO L. C. LARIEIRA ${ }^{3}$ \\ (iD) https://orcid.org/0000-0001-7674-6093 \\ LUIS H. C. PINOCHET ${ }^{4}$ \\ (iD) https://orcid.org/0000-0003-2088-5283
}

\section{INTRODUCTION}

This special edition of Mackenzie Management Review (RAM) was motivated by the joint perception of the editor-in-chief, Prof. Dr. Gilberto Perez, and the guest editors who signed this opening article, that digital transfor-

1 Pontifical Catholic University of Minas Gerais (PUC Minas), Belo Horizonte, MG, Brazil. E-mail: baroni@pucminas.br

2 School of Economics and Management of University of Lisboa, Lisboa, Portugal. E-mails: ampreis@ gmail.com and apreis@iseg.ulisboa.pt

3 Getulio Vargas Foundation (FGV) e Mackenzie Presbyterian University (UPM), São Paulo, SP, Brazil. E-mails: claudio.larieira@fgv.br and claudio.larieira@mackenzie.br

4 Federal University of São Paulo (Unifesp), São Paulo, SP, Brazil. E-mail: luis.hernan@unifesp.br

\section{(cc) $\mathbf{B Y}$}


mation is one of the most discussed topics recently in the organizational environment without a shared understanding of what it is about and what are its effects on business models from different industries.

Indeed, digital transformation is just like the new models of the various technological devices (smartphones, tablets, smart watches) that are used without us fully mastering their resources. It is happening in an accelerated way without even having a clear understanding of the phenomenon. It is typically a situation in which reality occurs at a speed greater than its understanding, thus claiming the researchers' positioning in the face of digital contemporaneity. Just like Uber, that initially imposed itself as a "de facto" reality (in practice) before becoming a de jure standard (supported by law), the research agenda digital transformation seeks to guide the future of research in the field, but, due to the speed of changes, it may fit into the metaphor of the lantern on the ship's stern, helping to illuminate the past. Even though the organizational practice is more agile than the academy, it is still worth emphasizing the fundamental role of research in interpreting the nuances of the phenomenon through the most diverse perspectives.

In addition to this introduction, this paper is structured as follows: the following section uses the Darwinian metaphor of the evolution of species to analyze the digital transformation; later, the framework of four strategic layers (tiers) that indicate the degree of digital transformation (Subramaniam, 2021) is presented and discussed to provide a common ground for research in the field; next, the six papers that compose this special issue are analyzed to draw a plot that illustrates the diversity and breadth of the research field; and finally, a future research agenda is proposed.

\section{DIGITAL TRANSFORMATION AND ORGANIZATIONAL ECOLOGY}

Darwin (1859) considers that species that survive and reproduce are not the strongest or the most intelligent, but the most adaptable to the environment. The transformation of species to achieve better performance through better adaptation to the environment resulted in the evolution of species, described by Darwin (1859) in the book Origin of species. The business environment is constantly changing and the only certainty is the increasing rate of change. Political, legislative (Moura \& Saroli, 2021) and technological changes powered by behavior shifts and market dynamics are frequently faced. 
With such growing change dynamics, organizational adaptability is essential for survival and success. The development of dynamic capabilities as a way to overcome challenges posed by the environment has already been studied in works such as Magistretti, Pham, and Dell'Era (2021) or Moura and Saroli (2021). Indeed, the ability to adapt comes from several aspects, such as the dynamic capabilities of its employees, and the ability to adapt the business model to the new reality, but such abilities often require the use of new technologies or innovative ways of using the existing technologies. In this sense, digital transformation is crucial for the survival and sustainable growth of the company (Kim, Choi, \& Lew, 2021).

Innovation in the use of technologies will enable this adaptation to new realities by supporting new business models and new ways of operating. By analyzing large volumes of data with different structures (big data), it is possible to understand the market preferences. By automating operations, it is possible to homogenize the company's behavior and, consequently, its performance throughout its geographic dispersion, achieving systematically a level of error lower than what the incidence of error would have been if the tasks had been performed by a human. Through technology, dispersed actions are coordinated, globally sourcing products and services, as well as selling to a global market; and for digital or digital-enabled products, such as movies, music, or CAD models for printing parts on 3D printers, one can not only take orders and pay online, but also deliver the item online. According to Kim et al. (2021), digital transformation involves IoT (internet of things), 5G wireless communications, cloud computing, big data, artificial intelligence, blockchain, and quantum computing.

Species adjustment is unavoidable, as seen in the organizational impact of the Covid-19 pandemic. The necessary confinements have radically changed the way the market buys: online sales and services substantially increased their market share. There was an abrupt drop in human passenger travel, while the transport of goods directly to the customer increased. The services had to be provided essentially online with an important role played by identification and contactless payments as a way of keeping operations safe during the pandemic (Obrenovic et al., 2020).

Considering the breadth and depth of the digital transformation phenomenon, the following section seeks to contribute to the presentation of a guiding framework for research in the field. 


\section{STRATEGIC TIERS TO DIGITAL TRANSFORMATION}

The revolutionary role that digital technologies are playing in the modern economy is notorious. Across all industries, the spread of digital technologies and the emergence of disruptive threats are transforming business models and processes (Rogers, 2016; Gimpel et al., 2018). The challenge most companies have not yet faced is: figuring out how to capture the different types of value these technologies can offer. Therefore, developing a digital transformation strategy that takes advantage of this value is not easy either, as it is a business strategy inspired by a digital technology that aims to deliver unique capabilities to respond to constant market changes (Sebastian et al., 2017).

Without a comprehensive assessment of what modern digital technologies can offer, companies tend to assume that any application will lead to a digital transformation, which in fact is not true. Many executives and managers make ad hoc business decisions about the use of digital technologies and end up struggling, even to maintain competitive parity, despite investments. Subramaniam (2021, in press) observes that companies may benefit from digital technologies from four strategic tiers that indicate the degree of digital transformation as shown in Figure 3.1.

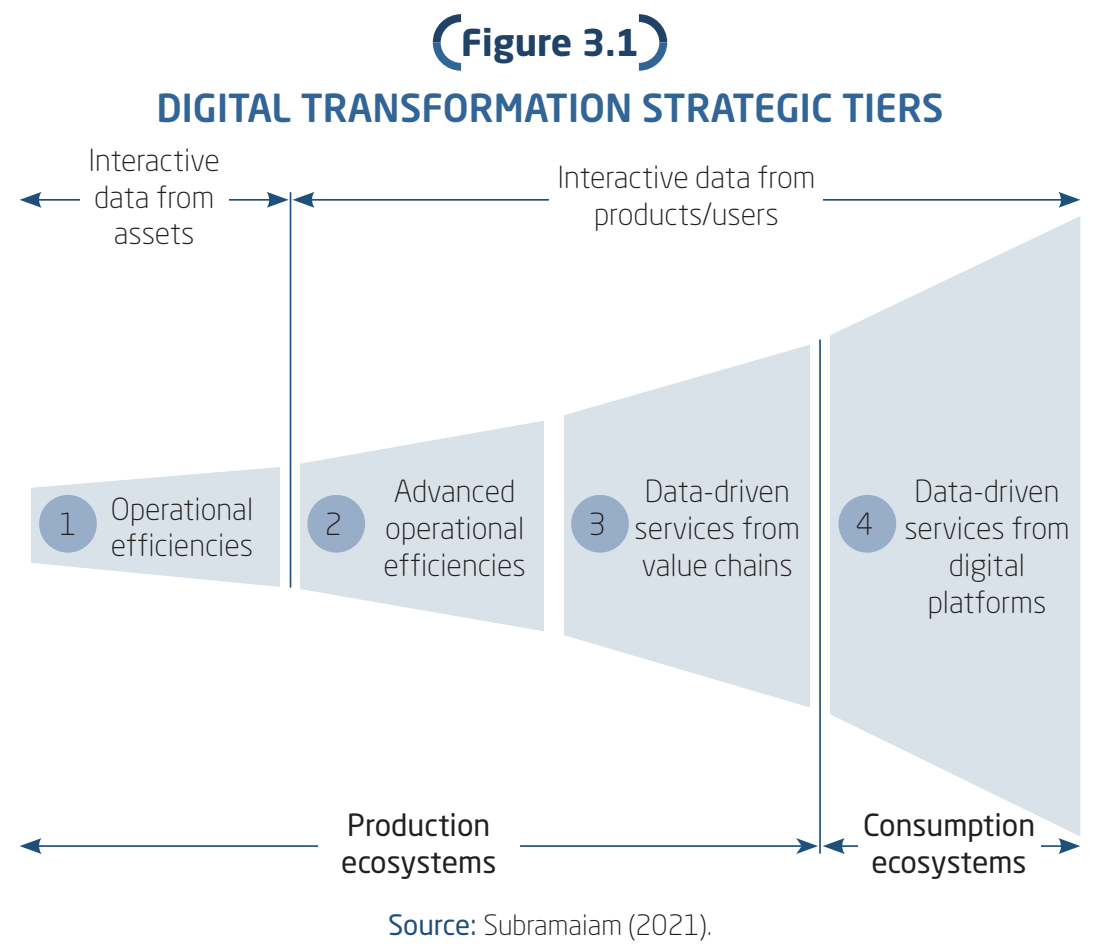


- First tier - "Operational efficiencies": in this case, the data is generated by Industry 4.0 technologies and companies (which have the same opportunities or face the same barriers) use this data to detect and prevent situations in real-time (Horváth \& Szabó, 2019). This layer becomes mandatory, as most companies can benefit from operational efficiency. The vast majority of digital transformation initiatives take place at this tier, which is especially important if operational efficiency is a large part of a company's strategic drive. The main challenges in this layer include the installation of interactive data generation in asset utilization and data sharing (Subramaniam, 2021).

- Second tier - "Advanced operational efficiencies": in this case, companies also benefit from operational efficiency gains, improving product development productivity. However, the difference is that the company uses data from digital technologies to observe customers using its products. This dimension of the customer presents additional challenges, as it allows consumers to have greater expectations in obtaining quality information, agility and opportunities to interact with companies (Piccinini, Gregory, \& Kolbe, 2013; Vial, 2019). Efficiency gains in this layer go beyond asset utilization. Thus, it is critical for companies that sell products with the potential to access user interactive data, which can be leveraged for strategic advantages beyond what is available in the first tier (Subramaniam, 2021). The primary use of interactive data enables businesses to improve advertising or efficiency in the development of products or services by expanding their analytical capacity (Contreras Pinochet, Amorim, Lucas, \& Souza, 2021). Furthermore, digital assets, digital agility, digital relationship and big data analytics are fundamental capabilities for digital transformation (Verhoef et al., 2021).

- Third tier - "Data-driven services from value chains": this layer involves changing the prevailing business model from one that is designed to produce and sell products to one that provides data-based services to digital customers in that digital technologies accelerate the speed of change (Warner \& Wäger, 2019). Companies must be digitally connected to receive, analyze, generate, share and react to their product data in real time. As new revenue streams are generated, the consequence is more than increasing operational efficiency. In this layer, companies recognize that they can generate data-based services from products and value chains. These companies must enrich their production ecosystems to extend their strategic advantage from operational efficiencies to new data-driven services. Such events may foster new business operations, facilitating 
and fully leveraging the core competence of companies through digital technology to obtain a competitive advantage (Brynjolfsson \& Hitt, 2000). Instead of companies using the data just for operational efficiency, they use such data for revenue generation. Many companies miss opportunities in this layer because they ignore the product consumption ecosystems or consider it too risky to increase the product capillarity to digital platforms (Subramaniam, 2021).

- Fourth tier - "Data-driven services from digital platforms": companies create virtual communities so that users can interact with each other. The companies' products generate user interaction data, which the company uses to facilitate exchanges between its digital customers and various third-party entities or partners outside its value chains. AI (artificial intelligence) algorithms can match specific users, analyzing product-user interaction data in the same way that application services relate customers and businesses from the data. In this case, companies will be able not only to generate new revenues from their data-based services, but also to extend their products to digital platforms. This digital transformation layer is the most challenging for industrial age companies and also for companies operating with value chain-oriented business models and little experience with digital platforms. This layer is seen as strategic and important for any company whose products have emerging consumer ecosystems. Companies that remain within their production ecosystems in such scenarios run the risk of being commoditized. In this case, increasing the capillarity of its products by taking them to digital platforms is the key challenge (Subramaniam, 2021).

The four tiers of digital transformation operate from modern digital technologies that have two directions for value: 1. data in its expanding new role; and 2. emerging digital ecosystems. Data used to be generated by discrete events, such as data exchange between stakeholders, but it is becoming increasingly interactive (continuously generated by typical IoT sensors and by technologies that perform information tracking).

Therefore, this continuous tracking of assets and their operating parameters can increase productivity. Consequently, such interactivity reverses the roles of products and data. Data traditionally support products, but products now increasingly support data. Products not only provide functionality, but they also help to build a brand or generate revenue. Therefore, data serve as conduits for interactive data and sources to enable business improvements, such as new customer experiences, optimizing operations, or even creating new business models (Fitzgerald, Kruschwitz, Bonnet, \& Welch, 2014). 
To leverage the new expansive function of interactive data, companies also need networks that generate data. Sensors connected to digital ecosystems can generate business value, directly and positively impacting the profitability of companies. The first three tiers depend on production ecosystems and the fourth on consumption ecosystems. The definition of a digital transformation strategy requires the assessment of the need to engage in each of the four tiers shown in Figure 3.1 and focus on investments that can help it reap the benefits of interactive data and ecosystems.

The tiers framework proposed by Subramaniam (2021) indicates that not all companies will want or will be able to engage in transformations in all four layers. Some organizations may choose to focus efforts on just one or a few of the layers, but all companies must certainly remain aware of the business ecosystem that is expanding into new possibilities (Hess, Matt, Benlian, \& Wiesböck, 2016; Matt, Hess, \& Benlian, 2015). Opportunities for using digital transformation strategies are plentiful and a well-conceived digital transformation strategy may keep the company competitive within its context. Considering that the framework of strategic tiers for digital transformation (Subramaniam, 2021) constitutes an important guide for research in the area, the exercise of classifying the six articles in this special issue into four layers is carried out next.

\section{DIGITAL TRANSFORMATION PERSPECTIVES OF THE STUDIES OF THE SPECIAL ISSUE}

The first paper in this special issue on digital transformation is entitled "Key dimensions of digital maturity: a study with retail sector companies in Brazil" and emblematically represents the need that academia and market professionals have to better understand this phenomenon of business digitization. Using a quantitative approach, a sample of 260 respondents from the Brazilian retail market was obtained and through structural equations (partial least square - PLS); eight dimensions that potentially contribute to the establishment of the digital transformation were evaluated. The survey results showed that the dimensions of strategy, market, operations, culture and technology are those that are most related to the development of digital maturity, which allows leaders and managers to make decisions and implement actions in the pursuit of digital transformation in their organizations more effectively. Considering the paper's focus on dimensions beyond operational efficiency with potential benefits not only for retail companies, but 
also for their customers, the research can be framed in the second tier, called advanced operational efficiencies (Subramaniam, 2021).

Still in the wake of digital maturity, the paper "Digital transformation in private Brazilian higher education institutions: pre-coronavirus baseline" discusses digital mastery (a likely synonym for digital maturity) in universities in Brazil based on surveys and interviews conducted together to managers of these institutions. Using a more qualitative and exploratory approach, this work has the merit of evaluating the digitization degree of this type of institution before the Covid-19 pandemic, which may represent a milestone and a benchmark to assess the acceleration of digital transformation after the end of the pandemic. The results outlined that the investigated universities already had a high level of digitization. As the digitization of educational environments encompasses not only operational activities, but also teaching modalities, this study can also be classified in the second layer, called advanced operational efficiencies (Subramaniam, 2021).

Several contemporary authors have tried to clearly define what digital transformation is, in fact, and how it differs from previous movements in the adoption of information technology (IT) in organizations. There are still some disagreements about the phenomenon itself, but there is already more understanding about the role of business transformation that digital transformation provides. In this sense, the paper "The role of big data stewardship and analytics as enablers of corporate performance management" demystifies the perception of some, that big data (an important element of digital transformation) refers only to technical issues. Through a survey carried out with 312 IT managers in Brazil, this study established more clearly the relationship between data administration and business analytics (BA) and their importance for the implementation of effective big data. Even more important is to understand the relationship between these three IT assets and how they can collaborate to manage corporate performance, which pragmatically demonstrates the importance of digital transformation in organizations. The paper works on a concept of corporate performance that goes beyond the most basic level of operational efficiency, being, thus, classified in the second layer of digital transformation (Subramaniam, 2021).

Blockchain is probably one of the greatest promises of digital transformation, given its potential to integrate processes, organizations, markets and societies. The paper "Implications of blockchain and transparency for business sustainability: an integrative review" addresses an important issue by investigating the literature on the use of blockchain in business segments beyond those already known, such as banks, insurance companies, finance 
companies, among others. As environmental, social and governance (ESG) is a current theme in academic and professional circles, discussing the adoption of blockchain platforms as levers for the implementation of sustainability in organizations, with their respective transparency, becomes a pressing need nowadays. As the application of the blockchain impacts the digital ecosystem of the organizations involved, the perspective adopted in the research can be linked to the $4^{\text {th }}$. digital transformation tier, called datadriven services from digital platforms (Subramaniam, 2021).

Discussing the use of open data made available by governments and organizations has become a trend, which is explored in the paper "Public value through technologies developed with open government data: the Love Serenade Operation case". Through a single case study, the authors collected data on the perception of citizens regarding the value that public data can bring to society, which makes the concept of digital transformation extend to other segments besides the for-profit business segments. Given the public bias of the research with impacts on government transparency and relationship with the citizen, the work fits into the highest layer (Subramaniam, 2021) by associating the concept of digital platforms not only with market relations, but also with a space of data-based public services.

Finally, the sixth and final paper in this special edition is in Spanish and is entitled "Corporate digital responsibility: foundations and considerations for its development". The paper introduces an important theme: the negative impacts of digital technologies on individuals, markets and society. Currently, there is a tendency to perceive only the benefits and positive impacts of adopting digital technologies that make up the digital transformation scenario, but authors and professionals are also beginning to question the not-so-positive impacts on employment, income, education, among others, bringing to light issues still little discussed in Brazil, but which are on the radar of reports by the World Economic Forum (WEF, 2020) on the impact of digital transformation in the workplace. The critical aspect of research with a broad perspective of the impacts of digital transformation is pertinent to the scope of the fourth layer of digital transformation (Subramaniam, 2021).

The diversity of works submitted and approved in this special issue reflects the broad spectrum of the research field of digital transformation. It is proposed to follow an agenda that helps to understand the borders and possibilities of this field that is yet to be explored, avoiding generic approaches that everything could be understood as digital transformation and also suggesting some better delimited investigation. 


\section{DIGITAL TRANSFORMATION RESEARCH AGENDA PROPOSAL}

The lack of clarity in the definition of constructs in the field of Administration and, in particular, in the field of information system management, is not new, as evidenced by Joia (2017). The marketing appeals of new technologies driven by consulting companies eager for new concepts and opportunities for training contracts constitute fertile ground for the flowering of buzzwords that become corporate fashion jargons after becoming viral on the Web and in airport bookstores.

Joia (2017) highlights that constructs are abstract definitions of observation categories, and such categories must be robust enough for observers to be able to recognize the construct in question. Joia (2017, p. 1) is emphatic in stating that "regardless of the epistemological line that one intends to follow in a research, the construct clarity to be studied is a necessary condition for the validity and reliability of the results". Recognizing that technological advances will bring the systematic emergence of new constructs in the informational field and the risk of studies that do not explore deeply their real meanings, Joia (2017) suggests the use of the Social Representation Theory (Moscovici, 1978) for a clearer definition of the constructs.

Citing Suddaby (2010), Joia (2017) outlined that the construct clarity comprises four main elements: the concept definition through language; the contextual conditions to which the construct may or may not apply; the semantic relationships of the construct with other constructs; and the construct's logical consistency in relation to the theoretical argument in which it is inserted. It must be recognized that the field of digital transformation is vast and still unstructured to be restricted to a parsimonious set of variables that explain the phenomenon. At the current stage, digital transformation studies are still far from meeting the four assumptions of Suddaby (2010). Notably, the imbricated relationships of the digital transformation construct with the industry 4.0 construct, which comprises enabling technologies (IoT, big data, AI, augmented virtual reality, cyber security, among others), violates the third assumption. Meira (2021) characterizes digital transformation as the result of the sum of digital innovation with strategic transformation, intertwining new managerial perspectives with digital platforms. Rogers (2016) highlights that digital transformation is not just a discussion about technology, but about how technology acts in five dimensions: customers, competition, data (understood as organizational assets), innovation and value. 
Therefore, some paths are proposed to guide researchers in the field. The basic recommendation is to delimit the context and the associated technology or technologies. Representing enabling technologies in a horizontal platform to support digital transformation and the industries as a vertical line, the possibility of better delimited research is perceived when choosing a particular industry (e.g., retail market, higher education institutions, public administration, such as in the examples in this special edition) combined with a single or a more restricted set of enabling technologies (e.g., blockchain, big data, as in the examples in this special edition). The Alexandrian inspiration of divide and conquer seems to be particularly useful at the current stage of research in digital transformation.

Returning to Darwin's approach (1859), evolutions led organizations to improve their performance, or even to remain viable. Companies adopted new or renewed processes that involved innovative ways of using technology, proceeding to digital transformations, whose extension will vary from industry to industry and from organization to organization, but will be, in some cases, unavoidable for survival. Certainly, such emerging, complex and highly context-sensitive challenges make up a promising research agenda in this coming decade.

Finally, the guest editors are grateful for the opportunity to contribute to this special edition and to the paper that opens the issue. It is worth thanking Prof. Dr. Anatália Saraiva Martins Ramos, from Federal University of Rio Grande do Norte, who collaborated extensively with the editors of this issue, but due to professional commitments previously assumed, she was not able to be involved in a timely manner with the development of this paper. We would also like to thank the RAM reviewers and editorial team who made this special edition possible. Due to the high number of article submissions in this special call, future current issues of RAM will contain papers that were submitted to the scope of this special edition. We wish that this special edition of digital transformation of RAM is just a catalyst for promising research in this field that impacts organizations and society.

\section{$\int$ REFERENCES}

Brynjolfsson, E., \& Hitt, L. M. (2000). Beyond computation: Information technology, organizational transformation and business performance. Journal of Economic Perspectives, 14(4), 23-48. 
Contreras Pinochet, L. H., Amorim, G. de C. B., Lucas, D., Júnior, \& Souza, C. A. de (2021). Consequential factors of Big Data's Analytics Capability: How firms use data in the competitive scenario. Journal of Enterprise Information Management. Ahead-of-print. doi:10.1108/JEIM-11-2020-0445

Darwin, C. (1859). On the origin of species by means of natural selection, or preservation of favoured races in the struggle for life. London: John Murray.

Fitzgerald, M., Kruschwitz, N., Bonnet, D., \& Welch, M. (2014). Embracing digital technology: A new strategic imperative. MIT Sloan Management Review, 55(2), 1-12.

Gimpel, H., Hosseini, S., Huber, R, Probst, L, Röglinger, M., \& Faisst, U. (2018). Structuring digital transformation: A framework of action fields and its application at ZEISS. Journal of Information Technology Theory and Application, 19(1), 31-54.

Hess, T., Matt, C., Benlian, A., \& Wiesböck, F. (2016). Options for formulating a digital transformation strategy. MIS Quarterly Executive, 15(2), 123-139.

Horváth, D., \& Szabó, R. (2019). Driving forces and barriers of Industry 4.0: Do multinational and small and medium-sized companies have equal opportunities? Technological Forecasting and Social Change, 146, 119-132. doi:10.1016/j.techfore.2019.05.021

Joia, L. A. (2017). A teoria da representação social e a definição de constructos na área de administração da informação. EnADI - Encontro Nacional de Administração da Informação - ANPAD, Curitiba, PR.

Kim, S., Choi, B., \& Lew, Y. K. (2021). Where is the age of digitalization heading? The meaning, characteristics, and implications of contemporary digital transformation. Sustainability, 13, 8909.

Magistretti, S., Pham, C. T. A., \& Dell'Era, C. (2021). Enlightening the dynamic capabilities of design thinking in fostering digital transformation. Industrial Marketing Management, 97, 59-70.

Matt, C., Hess, T., \& Benlian, A. (2015). Digital transformation strategies. Business \& Information Systems Engineering, 57(5), 339-343.

Meira, S. (2021). 21 anotações sobre 2021. Retrieved from https://silvio. meira.com/silvio/21-anotacoes-sobre-2021/

Moscovici, S. (1978). A representação social da psicanálise. Rio de Janeiro: Zahar.

Moura, G. B., \& Saroli, L. G. (2021). Sustainable value chain management based on dynamic capabilities in small and medium-sized enterprises (SMEs). International Journal of Logistics Management, 32(1), 168-189. 
Obrenovic, B., Du, J., Godinic, D., Tsoy, D., Khan, M. A. S., \& Jakhongirov, I. (2020). Sustaining enterprise operations and productivity during the Covid-19 pandemic: "Enterprise effectiveness and sustainability model". Sustainability, 12, 5981.

Piccinini, E., Gregory, R., W., \& Kolbe, L., M. (2015). Changes in the producerconsumer relationship towards digital transformation. Wirtschaftsinformatik Proceedings Conference, 12, 1634-1648.

Rogers, D. L. (2016). The digital transformation playbook: Rethink your business for the digital age. New York: Columbia Business School.

Sebastian, I. M., Ross, J. W., Beath, C., Mocker, M., Moloney, K. G., \& Fonstad, N. O. (2017). How big old companies navigate digital transformation. MIS Quarterly Executive, 16(3), 197-213.

Subramaniam, M. (2021). The 4 tiers of digital transformation. Harvard Business Review. Retrieved from https://hbr-org.cdn.ampproject.org/c/s/hbr. org/amp/2021/09/the-4-tiers-of-digital-transformation

Subramaniam, M. (in press). The future of competitive strategy: Unleashing the power of data and digital ecosystems. Cambridge, MA: The MIT Press.

Suddaby, R. (2010). Editor's comments: Construct clarity in theories of management and organization. Academy of Management Review, 35(3), 346-357.

Verhoef, P. C., Broekhuizen, T., Bart, Y., Bhattacharya, A., Qi Dong, J., Fabian, N. \& Haenlein, M. (2021). Digital transformation: A multidisciplinary reflection and research agenda. Journal of Business Research, $122(\mathrm{C})$, 889-901.

Vial, G. (2019). Understanding digital transformation: A review and a research agenda. Journal of Strategic Information Systems, (28), 118-144.

Warner, K. S. R., \& Wäger, M. (2019). Building dynamic capabilities for digital transformation: An ongoing process of strategic renewal. Long Range Planning, 52 (3), 326-349. doi:10.1016/j.lrp.2018.12.001

World Economic Forum (2020). The future of jobs 2020. Retrieved from http://www3.weforum.org/docs/WEF_Future_of_Jobs_2020.pdf

$\begin{array}{ll}\text { EDITORIAL BOARD } & \text { EDITORIAL PRODUCTION } \\ \text { Editor-in-chief } & \text { Publishing coordination } \\ \text { Gilberto Perez } & \text { Jéssica Dametta } \\ \text { Technical support } & \text { Language editor } \\ \text { Vitória Batista Santos Silva } & \text { Daniel de Almeida Leão }\end{array}$

Vitória Batista Santos Silva
Daniel de Almeida Leão 